\title{
Tobacco intervention research in low- and middle-income countries: lessons learned and future directions
}

\author{
Kenneth D. Ward \\ University of Memphis School of Public Health, and Syrian Center for Tobacco Studies, Guest Editor, Journal of Smoking \\ Cessation Email: kdward@memphis.edu
}

Treating tobacco dependence is paramount for global tobacco control efforts, but is often overshadowed by other policy priorities. As stated by Jha (2009), "cessation by current smokers is the only practical way to avoid a substantial proportion of tobacco deaths worldwide before 2050." Its importance is codified in Article 14 of the Framework Convention on Tobacco Control (FCTC), and in the WHO's MPOWER package of effective country-level policies. Unfortunately, only $15 \%$ of the world's population have access to appropriate cessation support ( $\mathrm{WHO}$, 2015). Moreover, parties to the FCTC have implemented only $51 \%$ of the indicators within Article 14, on average, which is far lower than many other articles (WHO, 2014). Further, commenting on the use of "O" measures (Offer help to quit tobacco use) in the MPOWER acronym, WHO recently concluded, "while there has been improvement in implementing comprehensive tobacco cessation services, this is nonetheless a most under-implemented MPOWER measure in terms of the number of countries that have fully implemented it" (WHO, 2015). To the detriment of global tobacco control efforts, only one in eight countries provides comprehensive cost-covered services, only one in four provide some cost coverage for nicotine replacement therapy, and fewer than one third provide a toll-free quit line (WHO, 2015).

Recently in the Lancet, three renowned global tobacco control experts-Martin Raw, Judith Mackay, and Srinath Reddy-recommended that it is "time to take tobacco treatment seriously," and they urged that FCTC parties implement Article 14 guidelines and "prioritise measures that will reach their entire populations, using measures that are affordable" (Raw, Mackay, \& Reddy, 2016).

This theme issue of the Journal of Smoking Cessation demonstrates that tobacco treatment, and research to support effective treatment, is being taken seriously in several low- and middle-income countries (LMICs). Several case studies and original empirical contributions from prominent tobacco intervention research groups working in LMICs, as well as international funders, highlight the important work being conducted in several global quarters, and share important lessons learned to help guide future work.

In his commentary for this theme issue, Professor Harry Lando reminds us that "providing tobacco cessation treatment is feasible even in countries with the fewest resources", and he does a laudable job of recommending a path forward to accomplish this (Lando, 2016). He places strong emphasis on building capacity for research and treatment, and disseminating low cost cessation strategies. There is a growing body of evidence supporting low cost nation-wide cessation interventions, including national automated text message support programs, which have been successfully implemented recently in Costa Rica (Gomez, 2015), the low-cost medication Cytisine (Walker et al., 2014; West et al., 2011), and routinizing the delivery of brief cessation advice during healthcare encounters (West et al., 2015).

The papers in this theme issue describe many challenges and successes around the globe in building capacity and adapting, evaluating, and disseminating effective treatments in LMICs. One strikingly common challenge is how to effectively integrate brief cessation counselling into healthcare practice. Patients view physicians as highly credible interventionists. However, although physicians can help patients quit (West et al., 2015), as a profession, they do not consistently or effectively provide cessation services (Abdullah \& Husten, 2004; Aung et al., 2014). The problem is multi-layered: many LMICs have high rates of tobacco use by physicians and other healthcare providers (Abdullah, Qiming, Pun, Stillman, \& Samet, 2013, Abdullah et al., 2014; Asfar, Al-Ali, Ward, Vander Weg, \& Maziak, 2011), which make them reluctant to champion their patients' quit attempts. Beyond this motivational issue, many physicians are skeptical that patients want their advice to quit smoking (Ossip et al., 2016; Prucha et al., 2015), do not view cessation as part of their jobs (Dozier 
et al., 2009; Tee, \& Hairi, \& Hairi, 2012), and misunderstand the harms of tobacco (Abdullah \& Husten, 2004; Asfar et al., 2011; Dogar, Elsey, Khanal, \& Siddiqi, 2016; Lando, 2016).

Medical students have similar knowledge deficits as their mentors about cigarette smoking (Dania, Ozoh, \& Bandele, 2015; Jradi \& Al-Shehri, 2014), and about emerging tobacco use methods, such as waterpipe (Alzayani \& Hamadehm, 2015; Babar \& Riaz, 2015). An obvious solution is to educate and train physicians in tobacco treatment early in their careers. The first step is to discourage medical students from using tobacco given that many physicians begin smoking during medical school (Abdullah et al., 2014; Alzayani \& Hamadehm, 2015; Senol, Donmez, Turkay, \& Aktekin, 2006). It also is important to improve tobacco treatment training in medical schools, but this is challenging. A recent group-randomized trial of tobacco treatment education in 10 US medical schools found little evidence that an intensive multi-modal curriculum (a web-based course, classroom demonstrations, and a clerkship booster session) improved treatment delivery skills compared to traditional (and less intensive) brief, didactic tobacco education (Ockene et al., 2016). There have been some recent efforts to improve tobacco training among medical and other healthcare professional students in LMICs, such as Project Quit Tobacco in India and Indonesia (Nichter, Nichter, \& Muramoto, 2010) and the Smokescreen Education Program in China (Richmond, 2004). However, researchers need to evaluate the effectiveness of these programs, and adapt them to different cultural settings.

Bolstering healthcare providers' motivation and skills is only one of several useful approaches to improve tobacco treatment in LMICs (Raw et al., 2016; WHO, 2008), but it represents "low hanging fruit" in terms of cost-effectiveness and reach. This theme issue highlights progress on several fronts that is relevant to efforts to better integrate tobacco treatment into healthcare. Global Bridges is a global alliance of healthcare providers to expand the reach of evidence-based tobacco dependence treatment, and to facilitate implementation of FCTC Article 14 (Kemper et al., 2016). Funded by Pfizer Medical Education Group and organized by Mayo Clinic, in its five years of existence, Global Bridges has trained more than 22,000 healthcare providers in 62 countries (e.g., Hawari \& Bader, 2014). A major goal of Global Bridges is to foster communication amongst network members to achieve broad reach; early evidence indicates this is being accomplished (Leischow et al., 2016). Ever-improving technology makes global communication easier, and lowers the cost of training interventionists and intervention researchers. Global Bridges has created a multilingual website and virtual community (www.globalbridges.org), and this and other systems are being used to remotely train, supervise, and mentor tobacco interventionists (Asfar, Ward, Al-Ali, \& Maziak, 2016; Selby et al., 2015). Another web-based resource, www.treatobacco.net, spon- sored by the Society for Research on Nicotine and Tobacco and the Society for the Study of Addiction, is likewise building treatment capacity by sharing evidence-based treatment approaches. These important initiatives are improving healthcare providers' motivation, resources, and skills, thereby helping to make tobacco dependence treatment a routine part of healthcare encounters around the globe.

Even with state-of-the art technological support, a continuing challenge is that evidence-based interventions developed in high-income countries are often not appropriate in LMIC settings without substantial adaptation (Asfar et al., 2016; Dogar et al., 2016). Asfar et al., 2016 describe how empirically supported behavioural cessation strategies developed and widely used in the US and UK, such as self-monitoring, nicotine fading, and social support enhancement, are not acceptable or useful in Syria. Likewise, studies from Pakistan and Syria suggest that adding pharmacotherapy to behavioural support in "real world" healthcare settings may not boost cessation rates beyond what is achievable by behavioural support alone (Asfar et al., 2016; Dogar et al., 2016).

There is still much to be done, and many challenges remain. As Professor Lando reminds us (Lando, 2016), tobacco intervention does not occur in a vacuum. Efforts to help smokers quit are more successful when linked to other tobacco control strategies, such as product labelling (Baskerville et al., 2016; Li et al., 2016) and community engagement (Ossip et al., 2016). Additionally, rigorous intervention research is needed in LMICs to adapt treatment approaches from other settings as well as develop, test, and disseminate "home grown" treatments that are appropriate to the specific culture and context. While funding for tobacco intervention research historically has been a challenge (Lando, 2016), funders such as the US National Institutes of Health (NIH), Cardiovascular Health Research in the Developing Countries (IC-Health), and Research for International Tobacco Control (RITC) have made important contributions. NIH has provided substantial ongoing support through several initiatives, including its International Tobacco and Health Research and Capacity Building Program, which was spearheaded by Fogarty International Center and supported by several other NIH institutes including the National Institute on Drug Abuse and the National Cancer Institute (Parascandola et al., 2016; Primack et al., 2006). This theme issue highlights the impressive progress these investments have generated and lessons learned to ensure that tobacco intervention continues to be front and centre in global tobacco control efforts.

\section{Acknowledgements}

I would particularly like to thank the assistant guest editor, Adam C. Alexander, MS, for all his invaluable help with this special issue, and the team of reviewers, for their timely comments and hard work. 


\section{Conflicts of interest}

None.

\section{References}

Abdullah, A. S. M., \& Husten, C. (2004). Promotion of smoking cessation in developing countries: a framework for urgent public health interventions. Thorax, 59, 623-630.

Abdullah, A. S. M., Qiming, F., Pun, V., Stillman, F. A., \& Samet, J. M. (2013). A review of tobacco smoking practices among physicians in China: 1987-2010. Tobacco Control, 22, 9-14.

Abdullah, A. S. M., Stillman, F. A., Yang, L. I., Luo, H., Zhang, Z., \& Samet, J. M. (2014). Tobacco use and smoking cessation among physicians in developing countries: a literature review (1987-2010). International Journal of Environmental Research and Public Health, 11, 429-455.

Alzayani, S., \& Hamadehm, R. R. (2015). Tobacco smoking among medical students in the middle east: identifying areas for intervention. International Journal for Innovation Education and Research, 3, 72-78.

Asfar, T., Al-Ali, R., Ward, K. D., Vander Weg, M. W., \& Maziak, W. (2011). Are primary health care providers prepared to implement an anti-smoking program in Syria?. Patient Education and Counseling, 85, 201-205.

Asfar, T., Ward, K. D., Al-Ali, R., \& Maziak, W. (2016). Building the tobacco treatment evidence base in the eastern mediterranean region: lessons learned by the Syrian center for tobacco studies. Journal of Smoking Cessation, 11, 116-123.

Aung, M. N., Yuasa, M., Moolphate, S., Kitajuma, T., Fukuda, H., Lorga, T. et al. (2014). Challenges for smoking cessation intervention as part of primary care health services in developing countries. Journal of Smoking Cessation, http://dx.doi.org/10.1017/jsc.2014.28.

Babar, N. F., \& Riaz, S. (2015). Prevalence and factors associated with sheesha smoking in a sample of medical students. Journal of Postgraduate Medical Institute, 29, 123-127.

Baskerville, N. B., Brown, K. S., Nguyen, N. C., Hayward, , L. Hayward, Kennedy, R. D., Hammond, D. et al. (2016). Impact of Canadian tobacco packaging policy on use of a toll-free quit-smoking line: an interrupted time-series analysis. CMAJ Open, 4, E59-E65.

Dania, M. G., Ozoh, O. B., \& Bandele, E. O. (2015). Smoking habits, awareness of risks, and attitude towards tobacco control policies among medical students in Lagos, Nigeria. Annals of African Medicine, 14, 1-7.

Dogar, O., Elsey, H., Khanal, S., \& Siddiqi, K. (2016). Challenges of integrating tobacco cessation interventions in TB programs: case studies from Nepal and Pakistan. Journal of Smoking Cessation, 11, 108-115.

Dozier, A. M., Ossip, D. J., Diaz, S., Sierra-Torres, E., Quinones de Monegro, Z., Armstrong, L. et al. (2009). Health care workers in the Dominican republic: self-perceived role in smoking cessation. Evaluation \& The Health Professions, 32, 144-164.

Gomez, E. W. (2015, March). Country perspective: Costa Rica's experience in being the first country to scale-up a national mCessation program. Presented at the 16th World Con- ference on Tobacco or Health, Abu Dhabi: United Arab Emirates.

Hawari, F., \& Bader, R. K. (2014). Advancing tobacco dependence treatment services in the Eastern Mediterranean region: international collaboration for training and capacitybuilding. Sultan Qaboos University Medical Journal, 14, 442447.

Jha, P. (2009). Avoidable global cancer deaths and total deaths from smoking. Nature Reviews: Cancer, 9, 655-664.

Jradi, H., \& Al-Shehri, A. (2014). Knowledge about tobacco smoking among medical students in Saudi Arabia: findings from three medical schools. Journal of Epidemiology and Global Health, 4, 269-276.

Kemper, K. et al. (2016). Developing and managing effective international cessation training partnerships. Journal of Smoking Cessation, 11, 78-89.

Lando, H. (2016). Commentary: promoting tobacco cessation in low- and middle-income countries. Journal of Smoking Cessation, 11, 66-69.

Leischow, S. et al. (2016). Global bridges: development and analysis of a tobacco treatment network. Journal of Smoking Cessation, 11, 90-98.

Li, L., Fathelrahman, A., Borland, R., Omar, M., Fong, G., Quah, A. et al. (2016). Impact of Graphic Pack Warnings on Adult Smokers' Quitting Activities: Findings from the ITC Southeast Asia Survey (2005-2014). Journal of Smoking Cessation, $11,124-134$

Nichter, M., Nichter, M., \& Muramoto, M. (2010). Project quit tobacco international: laying the groundwork for tobacco cessation in low- and middle-income countries. Asia-Pacific Journal of Public Health, 22, 191S-188S.

Ockene, J. K., Hayes, R. B., Churchill, L. C., Crawford, S. L., Jolicoeur, D. G., Murray, D. M. et al. (2016). Teaching medical students to help patients quit smoking: outcomes of a 10-school randomized controlled trial. Journal of General Internal Medicine, 31(2), 172-81.

Ossip, D. J. (2016). Lessons learned from twelve years of partnered tobacco cessation research in the Dominican republic. Journal of Smoking Cessation, 11, 99-107.

Parascandola, M. et al., (2016). The global laboratory of tobacco control: research to advance tobacco cessation in LMICs. Journal of Smoking Cessation, 11, 70-77.

Primack, A., Bloch, M., Haverkos, L., Gust, S., Hare, M., \& Smith, R. (2006). Launching the fogarty international center international tobacco control research and training program. Tobacco Control, 15(Suppl. 1) mm i1-i2.

Prucha, M. G., Fisher, S. G., McIntosh, S., Grable, J. C., Holderness, H., Thevenet-Morrison, K. et al. (2015). Health care workers' knowledge, attitudes and practices on tobacco use in economically disadvantaged Dominican republic communities. International Journal of Environmental Research and Public Health, 12, 40604075.

Raw, M., Mackay, J., \& Reddy, S. (2016). Time to take tobacco dependence treatment seriously. The Lancet, Jan 20. pii: S01406736(15)00950-2. doi: 10.1016/S0140-6736(15)00950-2. [Epub ahead of print]. 
Richmond, R. (2004). The process of introducing a tobacco curriculum in medical school. Respirology, 9, 165-172.

Selby, P., Goncharenko, K., Barker, M., Fahim, M., Timothy, V., Drogonetti, R. et al. (2015). Review and evaluation of online tobacco dependence treatment training programs for health care practitioners. Journal of Medical Internet Research, 17, e97.

Senol, Y., Donmez, L., Turkay, M., \& Aktekin, M. (2006). The incidence of smoking and risk factors for smoking initation in medical faculty students: cohort study. BMCPublic Health, 6, 128.

Tee, G. H., Hairi, N. N., \& Hairi, F. (2012). Attitudes towards smoking and tobacco control among pre-clinical medical students in Malaysia. International Journal of Tuberculosis and Lung Disease, 16, 1126-1128.

Walker, N., Howe, C., Glover, M., McRobbie, H., Barnes, J., Nosa, V. et al. (2014). Cytisine versus nicotine for smoking cessation. New England Journal of Medicine, 371, 2353-2362.
West, R., Raw, M., McNeill, A., Stead, L., Aveyard, P., Bitton, J. et al. (2015). Health-care interventions to promote and assist tobacco cessation: a review of efficacy, effectiveness, and affordability for use in national guideline development. Addiction, 110, 1388-1403.

West, R., Zatonski, W., Cedzynska, M., Lewandowska, D., Pazik, J., Aveyard, P. et al. (2011). Placebo-controlled trial of cytisine for smoking cessation. New England Journal of Medicine, 365, 1193-1200.

World Health Organization (2008). WHO report on the global tobacco epidemic: The MPOWER package. Geneva: Switzerland.

World Health Organization (2014). 2014 global progress report on implementation of the WHO Framework Convention on Tobacco Control. Geneva: Switzerland.

World Health Organization (2015). WHO report on the global tobacco epidemic: Raising taxes on tobacco. Geneva: Switzerland. 